\title{
In-vitro Growth and Inhibition Studies of Tribulus Terrestris on Calcium Oxalate Monohydrate Crystals
}

\author{
R. Selvaraju ${ }^{1}$, S. Sulochana ${ }^{2}$ \\ Department of Engineering Physics, Annamalai University, Annamalai nagar-608002, Tamil nadu, India
}

\begin{abstract}
Problem statement: A many number of people in this world are suffering from urinary stone problem in different age groups. Nephrolilthiasis is the term given to a metabolic conditions in which the signs and symptoms results from the deposition of crystals of Calcium Oxalate Monohydrate (COM) in various connective tissues. Approach: It was quite very difficult to grow good quality of large COM crystals because COM was having very low solubility in any known solvents. Results: Attempts were made in the present investigation to grow COM crystals in vitro by single diffusion gel growth technique which is quite suitable to mimic the growth of COM crystals in vivo up to a certain extent. Good quality tiny crystals were grown by gel method which was characterized by FTIR, Powder Xray diffraction and Thermo gravimetric analysis. The characterization study confirmed the formation of COM crystals in the experiments. Herbal extract solutions of tribulus terrestris were used for the growth inhibition study of calcium oxalate crystals. Aqueous herbal extract solutions were powdered as supernatant solution along with the control solution on the set gels during the growth experiment. Conclusion: Tribulus terrestris extract dissolved COM crystals after 21 days of pouring the supernatant solution on the gel. This in vitro study may be helpful for in vivo studies, which may further lead to develop a preclinical formulation for kidney stone treatment.
\end{abstract}

Keywords: COM crystals, powder X-ray diffraction, thermal stability, herbal extracts

\section{Introduction}

The formation of urinary calculi is known as nephrolithiasis. Urinary calculi affected to many people in various age groups in this world. Urinary calculi is one of the most hazardous and painful existing urological disorder causing threat to the global population (1-2). The mechanism of formation of the biological crystals involves the combinations of organic and inorganic chemical compositions. The crystalline deposition is due to trace element in blood vessels, urinary tract, kidney urinary bladder and gallbladder in human beings. Since ancient times and an estimate recurrence rate of 50\% (3-4). Hence nephrolithiasis is a significant health problem. Analysis of stone compositions have clearly reported that calcium oxalate is the most frequent crystalline phase in human stones and calcium oxalate is the primary constituent of the majority stones(5). Calcium oxalate has low solubility in water cand crystallizes in 3 hydrated forms Calcium Oxalate Monohydrate (COM), Calcium Oxalate Dihydrate (COD), and Calcium Oxalate Trihydrate (COT). Among these COD and COT are difficult to form urinary stone because they are unstable and easy to eject from body along with urine(6). COM is the most thermodynamically stable form of calcium oxalate and occupies in biggest proportion of all the urinary stones(7-8). Several steps are involved in the formation of the crystals, which are nucleation growth and aggregation. The urinary stone formation begins from the occurrence of nuclei and the formation of these nuclei is from supersaturated urine. The super saturation also depends on urinary $\mathrm{PH}$, ionic strength, solute concentration of certain glycoprotein's and the pathogenic factors, which are quite complex and are studied (9). Many researchers have attempted to grow COM crystals by gel growth method (10). From this description of accumulated knowledge about the role of calcium oxalate crystals in urinary stone as well as urolithiasis. The slow and controlled diffusion of nutrients to the growing crystals in the gel medium is very useful to study the growth and inhibition conditions, which can be extended to urinary calculi by adding different inhibiting solutions. An important to grow and characterize COM crystals and study the inhibitive effect of various herbal extracts on its growth. The growth and inhibition study provides very useful information regarding the potent herbal extracts or herbal formulations, which can inhibit the growth of crystals in vitro and may be useful in prevention and cure of this crystal induce ailments.

In the present work, the in-vitro growth of calcium oxalate monohydrate crystal by single diffusion gel growth method in silica gel medium. The harvested crystals were studied by FTIR spectroscopy, powder XRD, thermal analysis by TGA/DTA and the effect of aqueous extracts of Tribulus terrestris are studied on the inhibition of growth in the COM crystals.

\section{Materials and Methods}

\subsection{Crystal growth}

The single diffusion gel growth method was used to grow calcium oxalate monohydrate crystal. Distilled water and AR grade chemicals were used to grow the crystals.

The glass test tubes of $25 \mathrm{~mm}$ diameter and $150 \mathrm{~mm}$ length were used as crystal growth apparatus. Sodium metasilicate (SMS) solution of 1.03 specific gravity was used to prepare the gel. The sodium meta silicate solution was mixed with $5 \%$ acetic acid and PH is adjusted to 6 . One of the reactant calcium chloride is incorporated inside the gel. After setting the gel, an aqueous solution of oxalic acid was slowly poured over it. Immediately a white column of tiny crystals were 


\section{International Journal of Science and Research (IJSR) \\ ISSN (Online): 2319-7064}

Index Copernicus Value (2013): 6.14 | Impact Factor (2015): 6.391

grown, which are shown in Fig 1. The chemical reaction inside the gel can be expressed as

$$
\mathrm{CaCl}_{2} \cdot \mathrm{H}_{2} \mathrm{O}+\mathrm{C}_{2} \mathrm{O}_{4} \rightarrow \mathrm{CaC}_{2} \mathrm{O}_{4}+2 \mathrm{HCL} \text {. }
$$

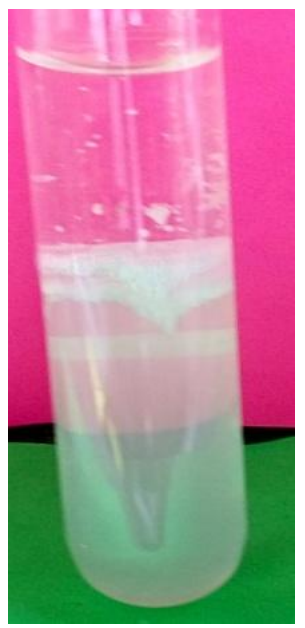

Figure 1: Growth of COM Crystals in Gel Medium.

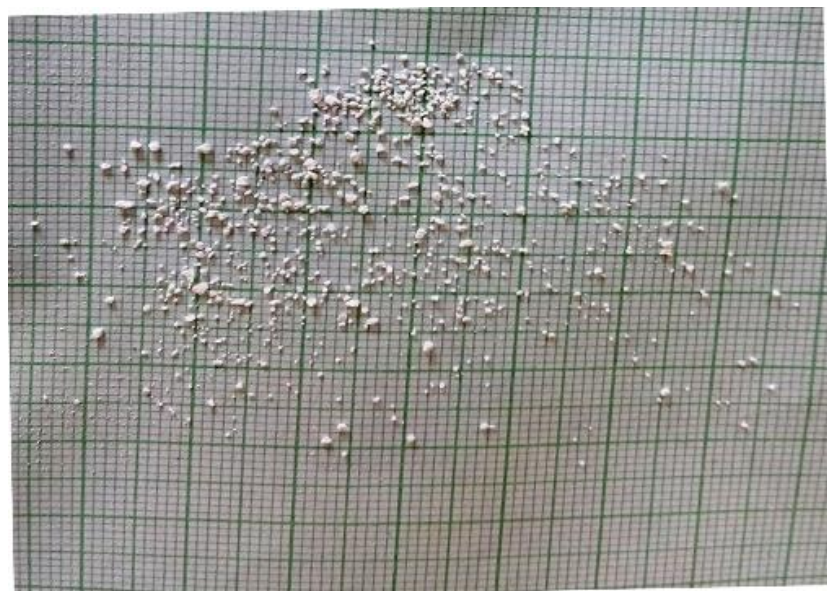

Figure 2: Calcium Oxalate Monohydrate crystal

The COM crystal as shown in fig. 2. The harvested crystals are characterized by FTIR, XRD and TG/ DTA techniques.

\subsection{Herbal Extract Preparation}

The dried and matured seeds of Tribulus terrestris were collected from Botanical garden, Department of Botany, Annamalai University. The collected seeds air-dried fine powder of the fruits of Tribulus terrestris. The aqueous extract of tribulus terrestris is prepared with $12.5 \mathrm{gm}$ of the fine powder of the fruits of tribulus terrestris boiled in $200 \mathrm{ml}$ distilled water for 30 minutes and then filtered twice by whatman No.1filter paper. The extract solution are stored in sterile bottles and kept at $-20^{\circ} \mathrm{C}$. The aquesous extract of Tribulus terrestris diffferent concentration using the COM crystal.

\subsection{Characterization Techniques}

Fourier transform infrared spectrum is recorded by $\mathrm{KBr}$ pellet technique using Nicolet IS5 model FT-IR spectrometer with the range 400-4000cm-1 to confirm the functional groups and the formation of the crystalline compound. Powder X-ray diffraction of the samples are carried out by EXPERT-PRO diffractometer with $\operatorname{CuK} \alpha$ radiation $\left(\lambda=1.5418 \mathrm{~A}^{0}\right)$. The powder XRD data are comparing the JCPDS file.The TGA/DTA spectrum obtained by NETZSCH STA 449F3 heating sample from room temperature to $600^{\circ} \mathrm{C}$ in an atmosphere of nitrogen with heating rate of standard procedure.

\section{Results and Discussion}

The single gel method is found to be simple method to grow COM crystals. This method provided to understand the growth of urinary crystal in-vitro.

\subsection{Fourier Transform Infrared Spectral Analysis}

The FT-IR spectrum of COM crystal as shown in fig. 3 and FT-IR assignments of COM crystal are listed in the table 1. The absorbtion peaks at $3430 \mathrm{~cm}^{-1}$ and $3254 \mathrm{~cm}^{-1}$ are due to $\mathrm{O}-\mathrm{H}$ strecting vibration respectively. $1620 \mathrm{~cm}^{-1}, 1316 \mathrm{~cm}^{-1}$ and $1031 \mathrm{~cm}^{-1}$ are due to $\mathrm{C}=\mathrm{O}$ strecthing vibrations. $947 \mathrm{~cm}^{-1}$ are due to $\mathrm{C}=\mathrm{O}$ strecthing vibration. $884 \mathrm{~cm}^{-1}$ and $781 \mathrm{~cm}^{-1}$ are due to $\mathrm{C}-\mathrm{C}$ strecthing vibration. $518 \mathrm{~cm}^{-1}$ are due to presence of oxygen-calcium bond.

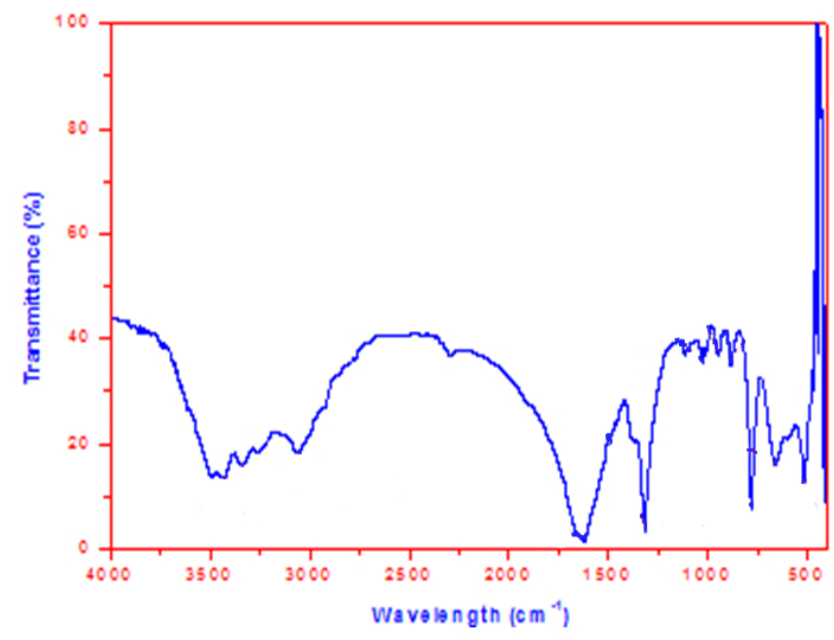

Figure 3: FTIR Spectrum of COM Crystals

Table 1: Assignment of Wave Number of COM Crystal

\begin{tabular}{|c|c|}
\hline Wave number in $\mathrm{cm}^{-}$ & assignments of peaks /bands \\
\hline 3430 & Asymmetric $\mathrm{OH}$ stretching \\
\hline 3063 & Symmetric $\mathrm{OH}$ stretching \\
\hline 3254 & Intermolecular $\mathrm{H}_{2}$ bonded OH stretching \\
\hline 1620 & Asymmetric $\mathrm{C}=\mathrm{O}$ stretch \\
\hline 1316 & Symmetric $\mathrm{C}=\mathrm{O}$ stretch \\
\hline 1031 & Asymmetric C-O stretch \\
\hline 947 & Symmetric C-O stretch \\
\hline 884 & C-C stretch \\
\hline 781 & O-C =O \\
\hline 661 & OH wagging \\
\hline 518 & M-O \\
\hline
\end{tabular}




\section{International Journal of Science and Research (IJSR) \\ ISSN (Online): 2319-7064}

Index Copernicus Value (2013): 6.14 | Impact Factor (2015): 6.391

Table 2: Powder XRD data of COM Crystals

\begin{tabular}{|c|c|c|c|c|}
\hline $2 \theta$ & $d$-spacing & Intensity & $F W H M$ & hkl value \\
\hline 15.08 & 5.7739 & 46.7 & 0.5217 & 021 \\
\hline 24.53 & 3.6450 & 84.7 & 0.1993 & 040 \\
\hline 30.27 & 2.9307 & 48.0 & 0.1907 & 123 \\
\hline 36.14 & 2.4821 & 20.6 & 0.2015 & 052 \\
\hline 38.41 & 2.3536 & 46.0 & 0.2840 & 061 \\
\hline 40.15 & 2.2459 & 13.4 & 0.2417 & 202 \\
\hline 43.79 & 2.2061 & 17.5 & 0.3043 & 143 \\
\hline 47.44 & 1.9112 & 14.3 & 0.3010 & 242 \\
\hline 51.07 & 1.7944 & 18.4 & 0.3108 & 342 \\
\hline 52.83 & 1.7431 & 12.8 & 0.3180 & 163 \\
\hline
\end{tabular}

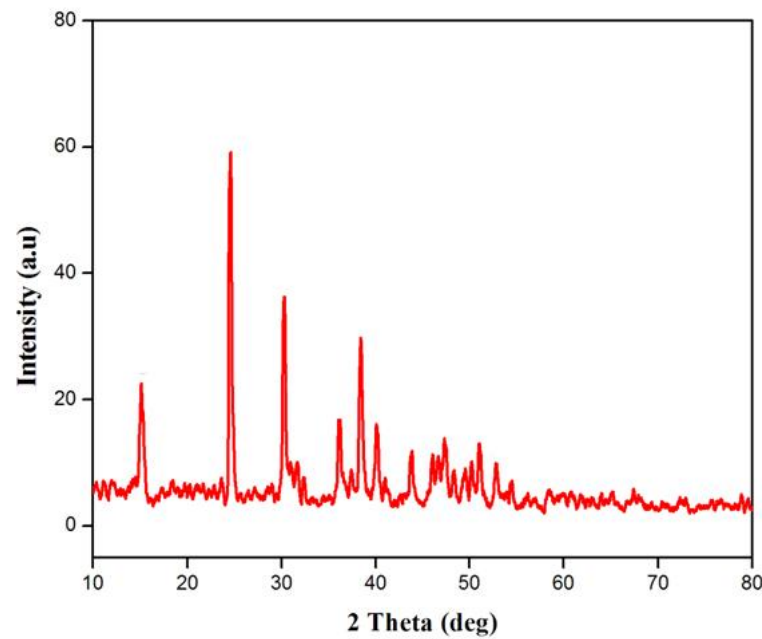

Figure 4: X-Ray Diffraction Pattern of COM Crystal

\subsection{Powder x-ray diffraction of Com Crystal}

The powder XRD pattern of COM crystal is shown in fig4 and Table 2 gives the data. The data confirm the presence of Calcium Oxalate Monohydrate in the form of whewellite $\mathrm{CaOx}$ vide JCPDS card 77-1160. The results confirm the purity and crystalline nature form. The COM crystal system is monoclinic.The lattice parameters of COM crystal is $\mathrm{a}=6.24, \mathrm{~b}=14.58$ and $\mathrm{c}=9.89$ respectively. The samples are highly crystalline in nature. The results of the pure crystal are in good agreement with the reported to the value.

\subsection{Thermal Analysis of COM Crystal}

TGA/DTA curves recorded for COM crystal as shown in fig 5. The loss of water crystallization in first step, carbon monoxide in second step, and carbon-di-oxide in third step. In the first stage weight loss of about $3 \%$ occurs between $20^{\circ} \mathrm{c}-140^{\circ} \mathrm{c}$ which indicates the loss of water hydration. In the second stage weight loss about $15.15 \%$ occured at temperature range between $140^{\circ} \mathrm{c}-240^{\circ} \mathrm{c}$ corresponding to dehydration of sample in first stage. In the third stage weight loss of $20 \%$ was observed between $240^{\circ} \mathrm{c}-510^{\circ} \mathrm{c}$. The decomposition of $\mathrm{COM}$ with realsing of $\mathrm{Co}_{2}$.

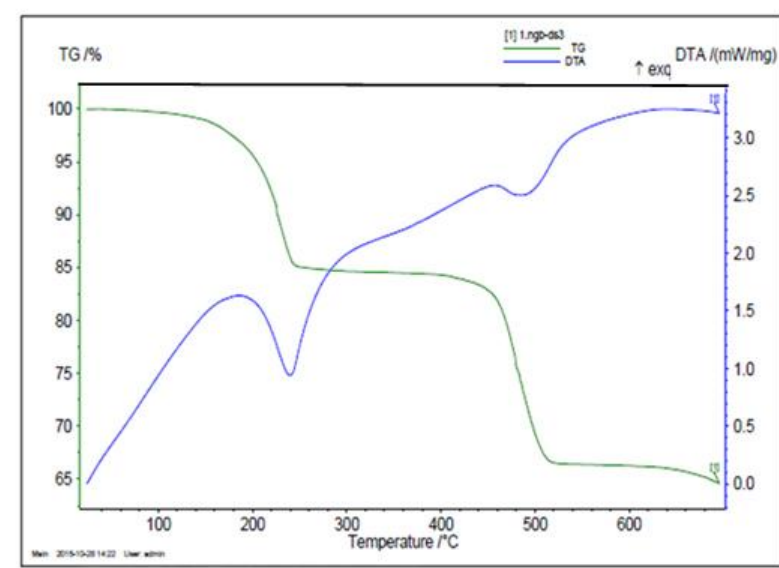

Figure 5: Thermogram of the COM Crystals

The observed and theoretical mass loss of COM crystals was given in tables. These results suggest that thermal stability of COM crystal.

Table 3: Mass Loss Percentages of COM Crystals.

\begin{tabular}{|c|c|c|}
\hline $\begin{array}{c}\text { Temperature } \\
\left({ }^{0} \mathrm{C}\right)\end{array}$ & $\begin{array}{c}\text { Observed weight } \\
(\%) \text { calculated }\end{array}$ & $\begin{array}{c}\text { Practical weight } \\
(\%) \text { from graph }\end{array}$ \\
\hline $20-140$ & $3.08 \%$ & $3.12 \%$ \\
\hline $140-240$ & $15.15 \%$ & $15.26 \%$ \\
\hline $240-510$ & $20.33 \%$ & $20.45 \%$ \\
\hline
\end{tabular}

\subsection{Diffusion and inhibition study}

Many author have studied the growth of inhibition of COM crystal. In the present investigation, the inhibitive study of $\mathrm{COM}$ is carried out by considering change in the mass value of diffusion co-efficient of $\mathrm{ca}^{2+}$ due to the presence of Tribulus terrestris extract solution.

The inhibition of COM crystal growth followed by the extract of Tribulus terrestris

This study is inference to useful to formulate the necessary Tribulus terrestris dosages to recurrence and prevent of urinary calculi formation.

Table 4: Observed Crystal Mass

\begin{tabular}{|c|c|c|c|}
\hline Solution & $\begin{array}{c}\text { Initial } \\
\text { Mass of } \\
\text { Crystal }\end{array}$ & $\begin{array}{c}\text { Mass of } \\
\text { crystal } \\
\text { after 7 } \\
\text { days }\end{array}$ & Remarks \\
\hline pure & & 0.332 & No change \\
\hline $\begin{array}{c}\text { Calcium oxalate } \\
\text { distilled water }\end{array}$ & 0.332 & 0.293 & Minute change \\
\hline $\begin{array}{c}\text { Calcium oxalate+ } \\
\text { 1\% T.terrestris }\end{array}$ & 0.315 & 0.204 & $\begin{array}{c}\text { After 12 days crystals } \\
\text { completely dissolved }\end{array}$ \\
\hline $\begin{array}{c}\text { Calcium oxalate+ } \\
\text { 2\% T.terrestris }\end{array}$ & 0.296 & \multicolumn{2}{|c}{} \\
\hline
\end{tabular}

The inhibition of COM crystals increase as the concentration of Tribulus terrestris increases the number of grown crystals and their average size decreases.The Tribulus terrestris growth of COM crystals in-vitro. The dissolution time of grown COM crystal depends on the concentration of Tribulus terrestris added in the supernatant dissolution occurs faster. This also confirms that Tribulus terrestris readily forms complex with calcium and inhibits the growth of crystals. 


\section{International Journal of Science and Research (IJSR) \\ ISSN (Online): 2319-7064}

Index Copernicus Value (2013): 6.14 | Impact Factor (2015): 6.391

Calcium oxalate has low solubility in water and crystallizes in 3 hydrated forms COM,COD, and COT. COM is the most thermodynamicaly stable form of calcium oxalate and occupies the biggest proportion of all the urinary stones(11). Calcium oxalate mainly forms due to the reaction between the calcium ion and the oxalate ion of oxalixc acid. Suryawanshi et al. have studied the growth and study of micro-crystalline calcium oxalate monohydrate crystals by agar gel system(12).

FT-IR spectrosopy is an exccellent tool to identify various chemical bonds in a compound. Valarmathi et al. have reported the powder IR spectra of tiny crystals of calcium oxalate monohydrate. The FT-IR spectroscopic study have proved the presence of all functional groups and bonds in calcium oxalate crystals (13).

Vijaya et al. have reported the powder XRD patterns and d values, unit cell parameters of calcium oxalate monohydrate were reported. The powder XRD tophaceous deposits in urinary stone also pin points calcium oxalate as the prime accuse. It is very difficult to obtain the single crystal XRD data on the present calcium oxalate monohydrate crystals because they get tube upon exposure of the atmosphere. However, the present powder XRD study suggests that samples are highly and well crystalline nature(14).

Thermo gravimetric analysis is performed to assess the thermal stability of the substances. Earlier E.L. Simons et al. have reported whereas a very small difference in observed and theoretical values was may be due to that, the quality of thermo gravimetric measurement of COM is affected by the three common experimental variables, heating rate, shape of sample container and size of sample(15).

The growth and inhibition study of various bio-material crystals, particularly responsible for ailments related to urinary stones were studied. Joshi et al. reported the effect of herbal extracts on the growth of calcium oxalate monohydrate. Barros et al. have reported the In-vitro studies in which calcium oxalate precipitation was induced by addition of $0.1 \mathrm{~m}$ sodium oxalate to unfiltered urine samples from wistar rats and normal humans in absence and presence of phyllanthus niruri extract suggested that extract may interfere with early stages of stone formation(16).

Rathore et.al. have reported the effect of ingestion of $3 \mathrm{~g}$ and $10 \mathrm{~g}$ tamarind pulp (Tamarindus indicus) was studied in normal subjects and in stone formers. Tamarind intake at the $10 \mathrm{~g}$ showed significant beneficial effect in inhibiting spontaneous crystallization in both normal subjcts and in stone formers (17).

Vargas reported the phycocyanin known antioxidant is reported to have potential antiurolitiatic activity as it reduces oxalate levels in kidney tissue significantly (18).

From the table 3 . One can easily note that $20 \mathrm{ml}$ tribulus terrestris COM give comparatively good inhibition than the others. But aqueous extract of tribulus terrestris was found to be an quickly active. These results were found to encouraging for the in vivo studies and the formulation of the drug. This study may be helpful to design the therapies for the prevention and cure of urinary stone.

\section{Conclusion}

Calcium Oxalate Monohydrate crystal were grown using gel method FTIR spectrum of COM crystals confirms the presence of a water crystallization $\mathrm{O}-\mathrm{H}, \mathrm{C}=\mathrm{O}, \mathrm{O}-\mathrm{C}$ bands are identified. The powder XRD results confirm the crystalline nature of the sample and identified the monoclinic crystal structure. The stepwise composition of sample confirmed the structure mechanism of COM crystals Tribulus terrestris extract in vitro growth inhibition study of COM crystal carried out at physiological temperature which could be useful for screening potent inhibitor. This could mimic the no growth of high concentration of Tribulus terrestris.

\section{References}

[1] Vladimir Uvarov, Inna popov, Nandhakishore shapur et.al X-ray diffraction and SEM study of kidney stones in Israel. Quantitative analysis crystallite size determinal and statistical characterization, Environ geochem Health. 33, 2011, 613-622.

[2] A. Mohamed ali, N. Arunainambi Raj, S. Kalainathan \& P. Palanichamy, Microhardness and acoustic behaviour of $\mathrm{CaOx}$ urimnary stone, Materials Letters.62, 2008, 2351-2354.

[3] Satherland Jw,Parks JH, and coe Fl, Recurrence after a single renal stone in a community practice, Miner Electolyte Metab 11, 1985, 267-269.

[4] 4.Yii-Her, Ching-chiu Li, Renal function in patients with urinary stones of varying compositions. Journal of material science 27, 20112, 64-267.

[5] Bak M.Thomsen JK,Jakobsen HJ, Peterson SE,"analysis of urinary stone Journal of urology". 164(2000) 856-863.

[6] Herremans D. Vandeursen H, Piltomvils "In vitro analysis of urinary computed tomography and bone densitometry Brit. Journal of urology 72(1993) 544-548.

[7] P. Sayan, S.T. Sargut, B.Kiran Crystal Research Technology, 2009, 44,807.

[8] P.Thanasekarn, C.M.Liu, J.F. Cho et al. Inorganic chemistry communication 2012, 17,84.

[9] Y.Y shen, S. Li, A. Xie, colloids \& surface B:Biointerfaces, 2007, 58, 298.

[10] J.Y. Clerk,I.M. Thomson,S.M optenbery, Journal opf Urology 154(1995) 2020-2040.

[11] Narayana Swami V and Ali VS.Pashanbheda Journal Res. Indian Med 1967;1:242-249.

[12] V.B. Suryavanshi and R,T.Chaudhari, Effect of neutral gel calcium oxalate monohydrate crystals in gel. 2015, $6(1): 7-12$.

[13] D.Valarmathi,L.Abraham,S. Gunasekaran Indian journal of pure \&applied physics 48(1) 2010,36-38.

[14] Barros ME, Schor.N and Booim MA. Effect of an aqueous extract from phyllanthus niruri on calcium oxalate crystallization in vitro. 2006, 34:351-357.

[15] P.Vijaya, Shanmukhaprasad Gopi, Aushiq H.Wani,M.V. Rajasekaran, V.K. Supramanian "Effect of ethylenediaminetet acetic acid and aquasoft 330 on crystal growth and morphology of calcium oxalate. 23 (2012) 771-778.

[16] E.L.Simons, A.E. Newkirk Talanta 1964,11,549.

Volume 5 Issue 6, June 2016 www.ijsr.net 


\section{International Journal of Science and Research (IJSR) \\ ISSN (Online): 2319-7064}

Index Copernicus Value (2013): 6.14 | Impact Factor (2015): 6.391

[17] Vargas SR, Perez GS, Zavala SMA, Perz GC, Antiurolithiatic activity of Raphanus sativus extract on rats. J. Ethnopharmacol. 68:335-338.

[18] Rathore P, Pentdse AK, Handa S, Sharma K and singh $\mathrm{PP}$, Effectiveness of Tamarind therapy an calcium oxalate crystallization using thre different methods. Indian Journal of Clinical Biochem 1993,8, 136-143.

Volume 5 Issue 6, June 2016 www.ijsr.net 